\title{
College Students’ Psychological Crisis: Types, Factors and Countermeasures
}

\author{
Ping Li \\ College of Basic Sciences \\ Tianjin Agricultural University \\ Tianjin, 300384, China \\ liping790520@126.com
}

\author{
Zhi-po Zhang \\ School of Law \\ Nankai University \\ Tianjin, 300350, China
}

\author{
Qing-qing Wang, Jing-kun Yan \\ College of Basic Sciences \\ Tianjin Agricultural University \\ Tianjin, 300384, China
}

\begin{abstract}
Psychological crisis of college students means the discomfort or more serious psychological problems caused by not being able to well solve problems. It mainly includes the problem of learning, employment, interpersonal relationship, love and family and life direction. And the origin of the psychological crisis is that the basic needs of college students cannot be well satisfied. The best solution is prevention first, restraint second. As for the prevention and response of college students' psychological crisis, it needs the cooperation of students, colleges, family and society. Firstly, students are supposed to actively enhance their own volitional quality and learn to manage their emotions. Secondly, colleges should teach students the knowledge and skills responding with psychological cris is and build a set of clear-authority system to deal with college students' psychological crisis. Finally, students' parents and all sectors of society should tightly cooperate with colleges to help students prevent and eliminate psychological crisis so as to achieve overall development.
\end{abstract}

Keywords-college students; psychological crisis; types; factors; countermeasures

\section{INTRODUCTION}

College students are in the period of youth. Although having mastered certain knowledge after years of study and grown into adults from the image, they are not mature in many aspects, such as independent life, social experience, human behavior and mental health. The reason is that it's the first time for most of them to truly leave parents, so that they are more likely to fell rather great psychological pressure, anxiety, depression and emotional impulse even some serious mental diseases when there are some conditions or problems existing around them. In recent years, college students' suicide or hurting others are mostly related to their psychological crisis [1]. The so-called psychological crisis was first put forward by G.Caplan in 1954, that is, when a person is faced with a problem, his previous way of dealing with the problem and usual support system are not enough to cope with the immediate situation. As a result, they'll feel temporary psychological imbalance, namely psychological crisis [2].
Statistics show that more than $30 \%$ of Chinese college students have suffered from psychological disorders in recent years. Therefore, the psychological crisis of college students should not be neglected. Schools, parents and all sectors of society should pay full attention to it so as to help students grow up healthily and promote the harmony of campus and society.

\section{TYPES OF COLLEGE STUDENTS' PSYCHOLOGICAL CRISIS}

According to the research result of college students' psychological crisis factors (multiple choices can be selected) among Xi'an Jiaotong University in 2012 by the research group "Research on the Role of Counselors in the Prevention of Solving College Students' Psychological Crisis” of Chinese higher education student research branch, it showed that: There were $39.62 \%$ students who were confused after enrollment. Those who did not like college or major were $31.05 \%$. There were $20.19 \%$ had difficulty integrating into the new class. There were $29.52 \%$ not used to the course arrangement and not willing to attend classes. Homesick students are $32.59 \%$. $51.05 \%$ of these students are with high learning pressure. Those having poor relationship management were $38.29 \%$, having emotional confusion being $51.24 \%$. There were $69.52 \%$ students who had poor psychological adjustment [3]. In general, the types of college students' psychological crisis can be divided into the following categories: (1) Learning problems, such as colleges, majors, course arrangement, willingness to attend class and study pressure; (2) Employment problems. The problem will become more obvious as graduation approaches; (3) Interpersonal relationship problems, such as, immersed into a new class and student relation; (4) Love and family problems, such as, homesickness and emotional confusion. (5) Life direction problems, such as, confusion and psychological adjustment. In specific:

\section{A. Learning problems}

Study is the prime task of students. College is so different from senior high school at learning mode, atmosphere and requirements that not every student can well adapt to college 
life. Some students don't study hard at usual, and they won't have psychological problems when their final grades are not ideal; Some students who are not smart enough are likely to doubt themselves when their final grades are not satisfying after hard work; And those students who select double degrees and will feel depressed by the bad result due to the limited energy and ability. Therefore, the problem of learning should be given high priority, and the psychological crisis of students caused by learning dissatisfaction needs to be resolved in time.

\section{B. Employmentproblems}

Employment is a problem that cannot be avoided. There are various purposes of going to university, but one of them is employment. Everyone desires to work in a good company. However, college education has been popularized to some degree because of the continuous expansion of college students' enrollment in China. There are only a few hot majors attracting the "reservation" of enterprises. But there also exist some majors facing the risk of "graduation is unemployment". So, college students have certain pressure and tense with the uncertainty of employment. It is rather difficult for most students to find a satisfying work. And students in unpopular major may have more serious mental pressure.

\section{Interpersonal relationship problems}

Man is a social animal, so he has to live in groups. However, current college students are mostly single child in the family and more likely to be self-centered especially growing up in the rich living environment. They have trouble considering others' legitimate interests and demands in college, and it is so hard for them to immerse themselves into the dormitory and class for lacking of knowledge and skills of interpersonal communication. These students will feel isolated, fearful and lonely after a long time.

\section{Love and family problems}

Love is both from family and love. Most students never left their parents, so it is reasonable for them to miss parent when they begin independent life. For another, failure in love will bring severe emotion change, depression happening from time to time. In addition, some students will also suffer from the accidental loss of parents or one of them. At this time, how to bravely face the pain is also a matter of concern.

\section{E. Life direction problems}

We are learning from primary school to high school. It seems to be the target of most people to "get into a college". Lots of students don't think what to do and how to lead a life once in college. So, it is common but serious problem that college students will fell confused and aimless, not knowing the purpose and meaning of life. It is the "existential crisis" called by psychologist Brammer. Learning without goals is impossible, and college life without goals is lifeless. Among these psychological crises, the last one is particularly serious. Colleges and families should pay great attention to guide students to resolve such psychological crisis.

\section{FACTORS OF COLLEGE STUDENTS' PSYCHOLOGICAL CRISIS}

According to the mechanism of psychological crisis, college students will have the psychological imbalance when they can't well cope with the problems of study, employment, interpersonal relationship, love and family and life direction. And different students will adopt different countermeasure when they face the same situation, so they can get different results. Those students who are confident and independent are less likely to have psychological crisis, while students who are dependent, inferior, and weak are more likely to have psychological crisis.

These problems can be explained by Maslow's hierarchy of needs theory that can be divided into five levels: Physiological needs, Safety needs, Love and belonging, Respect and esteem and Self-actualization [4-5]. The poor academic performance of college students may lead to the unsatisfying need for respect, causing the game addiction, dropping out of school even hurting others. Interpersonal relationship refers to respect himself and others. Falling in love, immerse into the dormitory, class and the communication with parents belong to the demand for love and belonging. The loss of love and lacking belonging will make them produce psychological crisis. Obscure employment prospect may lead to the crisis of security demand. And most college students have no idea who they are and where they will go, which will cause severe psychological crisis. It is also normal for college students to face physiological needs. And what is important is to properly handle these needs. Otherwise, it may lead to criminal mentality.

\section{COUNTERMEASURES FOR COLLEGE STUDENTS' PSYCHOLOGICAL CRISIS}

\section{A. Objects of attention}

To prevent psychological crisis, special attention should be paid to the following groups of college students, that is, students whose needs cannot be effectively met, poor students needing respect, isolated students, students who lack love and lose parents and students who lack confidence and lose lover. These students should be the focus of attention because they are more likely to have psychological crisis. Besides, there are some early signs of psychological crisis, such as truancy, isolation, and discussion of suicide or the occurrence of worldweariness. And early detection of these signals is helpful for timely intervention and prevention

\section{B. Subject of implementation}

The prevention and response of college students' psychological crisis requires the cooperation of college, family and society. There is no doubt that colleges should have more influences in this process. Family and society have shaped students' personalities and attitudes, which cannot be changed overnight. School is an important place for college students to study and live where teachers, psychological counseling clinics and counselors should be involved to guide college students to effectively prevent psychological crisis [6-7]. Especially, counselors mainly solve students' problems. Because many of them have the same age with students, and they can be closer to 
students and timely know the condition of special group students. Thus, they have more advantage in guiding college students to prevent psychological crisis. What's more, parents are supposed to closely cooperate with colleges and counselors, and all sectors of society should also offer proper support to help students prevent and eliminate psychological crisis.

\section{COUNTERMEAsures}

Solving psychological crisis is not so simple, and the best solution is prevention first, restraint second.

\section{A. Prevention first}

Prevention is divided into general prevention and special prevention. The first one refers to the prevention without special direction. At first, students should actively improve their own volitional quality and learn to manage their emotions. Secondly, colleges can help students firm their confidence and train their patience through launching psychology courses, lectures or class publicity to help students understand the possibility and harm of problems occurrence and teach students corresponding knowledge and skills. And the special prevention means preventing psychological crisis with plan and purpose. For example, executing psychological communication with students who had failed multiple subjects and understand their thoughts so as to avoid serious psychological problems; understand the factors and results of those students who had suffered from being cheated and comfort their injured hearts.

\section{B. Restraint second}

For the psychological crisis that has already occurred, it can be divided into mild, severe and neurotic psychological crisis according to the severity. The mild one can be solved through counselors' intervention and deep communication. And the other two needs the intervention of professional psychological counseling agencies, and following observation is also needed later. Besides, it is very necessary to build a set of clearauthority system to deal with college students' psychological crisis and make fast reaction to the occurred psychological crisis. Firstly, endow head teachers or counselors with bigger disposal authority. Secondly, an associate director of related territory is supposed to take charge of these affairs to effectively mobilize school resource to solve students' psychological crisis. Finally, in order to ensure the professional solution of the psychological crisis, colleges should arrange more than three psychological counselors and professional psychological counseling places.

\section{CONCLUSION}

Psychological crisis of college students means the discomfort or more serious psychological problems caused by not being able to well solve problems. It mainly includes the problem of learning, employment, interpersonal relationship, love and family and life direction. And the origin is that their basic demand cannot be well satisfied. The best solution is prevention first, restraint second. The prevention and response of college students' psychological crisis need the cooperation of students, colleges, family and society. College students are supposed to actively enhance their own volitional quality and learn to manage their emotions. Colleges should teach students the knowledge and skills responding with psychological crisis and build a set of clear-authority system to deal with college students' psychological crisis and make fast reaction to the occurred psychological crisis. In addition, students' parents and all sectors of society should tightly cooperate with colleges to help students prevent and eliminate psychological crisis so as to make them have healthy psychology and achieve overall development.

\section{ACKNOWLEDGMENT}

I would like to thank the Tianjin Agricultural College's Teacher Education Reform and Innovation and Development Project (20170817) for the fund support of this paper.

\section{REFERENCES}

[1] J. Zhang, Y. Z. LIu and L. Sun, Psychological strain and suicidal ideation: A comparison between Chinese and US college student, Psychiatry Research, 2017, vol. 255, pp. 256-262.

[2] X. Chen and J. C. Jia, College students' psychological crisis and its early warning intervention mechanis m, Education Exploration, 2005, No. 6, pp. 110-111.(in Chinese)

[3] X. F. Chen, and B. Liang, Prevention and resolution of college students psychological crisis, Journal of College Advisor, 2014, No. 4, pp. 8789.(in Chinese)

[4] Y. Saeednia and M. MD. NOR, Measuring hierarchy of basic needs among adults, Procedia - Social and Behavioral Sciences, 2013, vol. 82, pp. $417-420$.

[5] W. L. Wu, The relationship between incentives to learn and maslow's hierarchy of needs, 2012, vol. 24, pp. 1335-1342.

[6] S. V. Joshi MD, S. N. Hartly BA, M. Kessler MD, M. Barstead BA, School-based suicide prevention: content, process, and the role of trusted adults and peers, Child and Adolescent Psychiatric Clinics of North America, 2015, vol. 24, pp. 353-370.

[7] I. Barna and D. Mircea, Psycho-pedagogical counselling. an important stage in students' teaching career orientation, Procedia-Social and Behavioral Sciences, 2015, vol. 180, pp. 1044-1049.

[8] F. Y. Sahin, School counselor's assessment of the psychological counseling and guidance services they offer at their schools, ProcediaSocial and Behavioral Sciences, 2012, vol. 47, pp. 327-339. 